\title{
IMPLEMENTASI KEBIJAKAN ADIWIYATA SEBAGAI UPAYA PENANAMAN NILAI PEDULI LINGKUNGAN DI MAN 2 KULON PROGO
}

\author{
IMPLEMENTATION OF ADIWIYATA POLICY AS AN EFFORTS OF PLANTING \\ ENVIRONMENTAL CARE VALUES IN MAN 2 KULON PROGO
}

\author{
Ami Fatikha Almas \\ Filsafat dan Sosiologi Pendikan, Kebijakan Pendidikan FIP UNY \\ amifatikha@gmail.com
}

\begin{abstract}
Abstrak
Penelitian ini bertujuan untuk mendeskripsikan pelaksanaan Kebijakan Adiwiyata Sebagai Upaya Penanaman Nilai Peduli Lingkungan di Madrasah Aliyah negeri 2 Kulon Progo. Penelitian Implementasi Kebijakan ini mengacu pada teori Implementasi dari Edward III yang menekankan pada empat aspek pokok Implementasi yakni, Komunikasi, Sumberdaya, Disposisi, dan Struktur birokrasi serta program-program adiwiyata yang dilaksanakan dalam upaya penanaman nilai peduli lingkungan dan kendala yang dihadapi sekolah dalam pelaksanaan kebijakan adiwiyata.

Jenis penelitian ini adalah deskriptif kualitatif. Penelitian dilakukan di Madrasah Aliyah Negeri 2 Kulon. Subjek dari penelitian ini adalah kepala sekolah, ketua tim adiwiyata sekolah, anggota tim adiwiyata sekolah, guru dan siswa. Teknik pengumpulan data yang digunakan oleh peneliti adalah observasi, wawancara, dan studi dokumentasi. Teknik analisis data menggunakan teori dari Miles dan Huberman Terkait keabsahan data peneliti menggunakan metode triangulasi sumber dan teknik.

Hasil penelitian adalah sebagai berikut : (1) (2) Implementasi kebijakan di MAN 2 Kulon Progo didukung oleh: a) Komunikasi dilakukan dengan mengadakan sosialisasi dari puskesmas daerah, dinas lingkungan hidup, dan sosialisasi kepada wali murid melalui raoat komite b) Sumber daya didukung ketersediaan SDM dan anggaran nasional dan orang tua siswa, c) Pelaksana kebijakan memiliki komitmen yang memadai, d) Struktur birokrasi termuat dalam SK Tim Adiwiyata Sekolah yang diterbitkan oleh kepala sekolah. (2) Pelaksanaan programprogram adiwiyata dalam upaya menanamkan nilai peduli lingkungan meliputi program gereen hous, komposter, bank sampah, keindahan dan kebersihan lingan serta kreasi sampah. (3) Kendala yang dihadapi sekolah yaitu sulitnya membiasakan siswa untuk peka dan tertib dalam membuang sampah pada tempatnya.

Kata Kunci: Implementasi Kebijakan Adiwiyata, Nilai Peduli Lingkungan, Madrasah Aliyah Negeri 2 Kulon Progo
\end{abstract}

\begin{abstract}
This study aims to describe the implementation of the Adiwiyata Policy as an Effort to Cultivate the Value of Environmental Care in the Madrasah Aliyah Negeri 2 Kulon Progo. This Policy Implementation Research refers to the Implementation Theory of Edward III which emphasizes on four main aspects of Implementation namely, Communication, Resources, Disposition, and Bureaucratic Structure as well as superficial programs implemented in an effort to instill values of environmental awareness and obstacles faced by schools in implementing policies adiwiyata.

This type of research is descriptive qualitative. The study was conducted at Madrasah Aliyah Negeri 2 Kulon. The subjects of this study were the principal, head of the school's adiwiyata team, school adiwiyata team members, teachers and students. Data collection techniques used by researchers are observation, interviews, and documentation studies. Data analysis techniques using the theory of Miles and Huberman namely, data collection, data condensation, data presentation, drawing conclusions. Related to the validity of the data the researchers used source triangulation methods and techniques.

The results of the study are as follows: (1) (2) Implementation of policies in MAN 2 Kulon Progo is supported by: a) Communication is carried out by conducting socialization from local health centers, environmental services, and socialization to student guardians through committee meetings b) Resources supported the availability of human resources and the national budget and parents of students, c) The policy implementers have adequate commitment, d) The bureaucratic structure contained in the School Team Adiwiyata Decree issued by the school principal. (2) Implementation of adiwiyata programs in an effort to instill the value of caring for the environment includes a program of housings, composters, waste banks, beauty and cleanliness of lingan and garbage creation. (3) The obstacle faced by schools is the difficulty in getting students to be sensitive and orderly in disposing garbage in their place.
\end{abstract}

Keywords: Implementation of Adiwiyata Policy, Environmental Care Values, Madrasa Aliyah Negeri 2 Kulon Progo 


\section{PENDAHULUAN}

Indonesia merupakan negara yang rawan akan bencana alam, hal ini disebabkan karena letak geografis Indonesia yang terletak di antara Benua Australia dan Asia, serta di antara Samudra Hindia dan Samudra Pasifik. Sedangkan secara astronomis letak Negara Indonesia yaitu antara $6^{\circ} \mathrm{LU}-11^{\circ} \mathrm{LS}$ dan $95^{\circ}$ BT- $141^{\circ}$ BT. Dan Indonesia merupakan negara dengan luas 1.905 juta kilometer dan memiliki kurang lebih 16 ribu pulau yang terbentang dari Sabang sampai Merauke. Selain bencana alam yang disebabkan oleh letak wilayah Indonesia, Indonesia juga memiliki banyak bencana yang merupakan akibat ulah manusia yaitu diantaranya banjir, tanah longsor, kekeringan dan kebakaran hutan. Sebagai contoh kerusakan lingkungan yang disebabkan oleh sampah plastik yaitu dikutip dari Jurnal Scientific Reports yang di publikasikan oleh majalah Nature dalam Nationalgeographic.co.id pada tanggal 18

September 2018 bahwa Kumpulan-kumpulan sampah plastik di Samudera Pasifik kini meluas dengan ukuran yang sepertinya tidak masuk akal. Kumpulan sampah-sampah plastik yang mengambang di lautan antara Hawaii dan California ini terus membesar hingga berukuran 1,6 juta $\mathrm{km} 2$. Selain bencana alam yang disebabkan oleh letak wilayah Indonesia, Indonesia juga memiliki banyak bencana yang merupakan akibat ulah manusia yaitu diantaranya banjir, tanah longsor, kekeringan dan kebakaran hutan. Dalam laman berita yang diakses dari CNN Indonesia yang dipublikasikan pada tanggal 21 Agustus 2019 menyebutkan bahwa Kementrian Lingkungan Hidup dan Kehutanan (KLHK) mengumumkan sekitar 72 persen masyarakat Indonesia kurang peduli dengan masalah sampah. Dari Badan Pusat Statistik (BPS) tahun 2018 menyebutkan Perilaku Ketidakpedulian Lingkungan Hidup dari indeks yang ditetapkan BPS 0 sampai 1 dan indeks yang paling rendah ialah terkait sampah yakni sebesar 0,72 persen.

Selain itu dari laman berita yang di akses melalui https://tirto.id/ pada tanggal 17
September 2019 fenomena kebakaran hutan yang baru-baru ini terjadi di Kalimantan disebabkan salah satunya karena praktik Land Clearing atau pembersihan lahan oleh beberapa perusahaan asing maupun lokal, lebih dari 42 perusahaan yang melakukan Land Clearing telah disegel oleh Kementrian Lingkungan Hidup Dan Kehutanan, perusahaan yang melakukan Land Clearing tersebut diantara berlokasi di Jambi, Riau, Sumatra Selatan, Kalimantan Barat dan Kalimantan Tengah. Perbuatan tidak bertanggung jawab ini menyebabkan banyak kerugian terhadap masyarakat Indonesia maupun alam Indonesia itu sendiri. Melihat persoalaan pengelolaan dan kerusakan lingkungan tersebut pemerintah berkomitmen dalam menjaga lingkungan hidup salah satunya melalui Lembaga Pendidikan. Untuk mendukung Perlindungan dan Pengelolaan Lingkungan Hidup melalui Satuan Pendidikan, maka Kementerian Lingkungan Hidup bekerjasama dengan Kementerian Pendidikan dan Kebudayaan untuk mengembangkan suatu program pengelolaan lingkungan yang di sebut dengan program Adiwiyata. Peraturan Menteri Lingkungan Hidup Republik Indonesia Nomor 05 pada Tahun 2013 tentang Pedoman Pelaksanaan Program Adiwiyata menyatakan bahwa sekolah Adiwiyata merupakan sekolah yang peduli serta berbudaya lingkungan dan juga program Adiwiyata ialah suatu program untuk dapat mewujudkan sekolah yang peduli serta juga berbudaya lingkungan. 
Tujuan Program Adiwiyata ini adalah untuk mendorong terciptanya pengetahuan serta juga kesadaran warga sekolah dalam pelestarian lingkungan hidup serta mewujudkan warga sekolah yang bertanggung jawab dalam upaya perlindungan dan pengelolaan lingkungan hidup melalui tata kelola sekolah yang baik untuk mendukung pembangunan berkelanjutan. Keuntungan bagi sekolah dari adanya program Adiwiyata ini adalah sekolah dapat menciptakan tempat pembelajaran bagi siswa mengenai nilai-nilai pemeliharaan lingkungan, sikap peduli lingkungan, dan pengelolaan lingkungan hidup dengan upaya meningkatakan perlindungan dan pengelolaan lingkungan melalui kegiatan pengendalian, pengendalian pencemaran, pengendalian kerusakan dan pelestarian fungsi lingkungan hidup sehingga tercipta kondisi dan proses belajar-mengajar yang lebih kondusif untuk siswa. Sementara manfaat program Adiwiyata bagi siswa adalah untuk menumbuhkan sikap kepedulian terhadap lingkungan dan untuk dapat memahami betapa pentingnya memelihara lingkungan dengan baik.

Madrasah Aliyah Negeri 2 Kulon Progo menjadi salah satu sekolah di Kabupaten Kulon Progo yang telah mengimplementasikan program Adiwiyata ini. Berawal dari keinginan untuk membentuk dan meningkatkan sikap dan perilaku peduli lingkungan, dari keinginan untuk membentuk sikap peduli lingkungan ini sekolah menyadari akan perannya memberi pengetahuan dan mengajarkan pada siswa mengenai ilmu lingkungan hidup, dan menanamkan sikap peduli lingkungan, sikap peduli lingkungan ini juga termasuk nilai karakter yang harus di tanamkan oleh sekolah. Madrasah Aliyah Negeri 2 Kulon Progo ini juga memiliki program-program yang dijalankan, yaitu: Kreasi sampah, bank sampah, green house, kebersihan dan keindahan lingkungan serta komposter, dalam menerapkan programprogram dengan tujuan sebagai upaya menanamkan karakter peduli lignkungan, sekolah masih memiliki kendala yaitu sulitnya membiasakan siswa untuk membuang sampah pada tempatnya.

\section{METODE PENE LITIAN}

\section{Jenis Penelitian}

Penelitian ini menggunakan metode penelitian kualitatif deskriptif.

\section{Waktu dan Tempat Penelitian}

Penelitian ini mulai dilakukan dari bulan Januari - Februari 2020 di Madrasah Aliyah Negeri 2 Kulon Progo Jl Khudori Wonosidi, Wates, Kabupaten Kulon Progo.

\section{Target/Subjek Penelitian}

Subjek dalam penelitian ini adalah; kepala sekolah, ketua tim adiwiyata, anggota tim adiwiyata, guru mata pelajaran dan siswa dengan melakukan wawancara mendalam.

\section{Data, Intrumen, dan Teknik Pengumpulan Data}

Dalam penelitian ini pengumpulan data dilakukan menggunakan teknik observasi, wawancara, dan dokumentasi. Instrumen yang digunakan yaitu pedoman observasi, pedoman dokumentasi dan pedoman wawancara.

Observasi dilakukan untuk mengamati situasi yang berkaitan dengan Implementasi kebijakan adiwiyata

Wawancara dilakukan guna mendapat informasi mengenai bagaimana implementasi kebijakan adiwiyata sebagai upaya penanaman nilai peduli lingkungan di Madrasah Aliyah Negeri 2 Kulon progo yang dilakukan kepada kepala sekolah, ketua tim adiwiyata, anggota tim adiwiyata, guru mata pelajaran dan siswa.

Studi dokumentasi dilakukan dengan cara mengambil foto dokumen-dokumen berkaitan dengan implementasi kebijakan adiwiyata.

\section{Teknik Analisis Data}

Teknik analisis data yang digunakan dalam penelitian ini adalah teknik analisis data kualitatif. Menurut Miles dan Huberman dalam Emzir (2012). Analisis data kualitatif adalah suatu proses analisis yang terdiri dari empat alur kegiatan yang terjadi bersamaan yaitu, pengumpulan data, reduksi data, penyajian data dan penarikan kesimpulan atau verivikasi. 


\section{Uji Keabsahan Data}

Uji Keabsahan data pada penelitian ini yaitu menggunakan Triangulasi Teknik dan sumber.

\section{HASIL PENELITIAN DAN PEMBAHASAN}

\section{Implementasi Kebijakan Adiwiyata Sebagai Upaya Penanaman Nilai Peduli Lingkungan Di Madrasah Aliyah Negri 2 Kulon Progo}

a. Komunikasi

Edward III dalam (Subarsono, 2008: 90) menjekaskan bahwa komunikasi merupakan suatu keberhasilan implementasi kebijakan mensyaratkan agar implementaator mengetahui apa yang harus dilakukan. Apa yang menjadi tujuan dan sasaran kebijakan harus ditransmisikan kepada kelompok sasaran (target group) sehingga akan mengurangi distorsi implementasi. Apabila tujuan dan sasaran suatu kebijakan tidak jelas atau bahkan tidak diketahui sama sekali oleh kelompok sasaran, maka kemungkinan akan terjadi resistensi dari kelompok sasaran.

Dalam konteks pelaksanaan adiwiyata di Madrasah Aliyah Negeri 2 Kulon Progo, sekolah melakukan komunikasi dengan pelaksana kebijakan dan juga dengan orangtua siswa.

1. Komunikasi dengan pelaksana

Komunikasi dengan pelaksana kebijakan dilakukan sekolah dengan membangun relasi dengan Dinas Lingkungan Hidup dan Puskesmas Daerah, selain itu sekolah juga mengundang dari Puskesmas. Dan komunikasi diantara pelaksana didalam sekolah itu sendiri, sekolah juga membentuk tim adiwiyata sekolah, selain itu sekolah juga memanfaatkan media sosial sebagai sarana komunikasi antar pelaksana yakni melalui Whatsapp grup.

2. Komunikasi dengan siswa dan orangtua siswa Komunikasi dengan siswa dan orang tua siswa dilakukan sekolah dengan cara membentuk tim adiwiyata siswa untuk siswa, dan sosialisasi melalui rapat komite. selain berkomunikasi secara langsung, sekolah juga memanfaatkan media sosial untuk mengkomunikasikan mengenai sekolah adiwiyata salah satunya melalui grup Whatsapp.

b. Sumberdaya

Edward III dalam (Subarsono, 2008: 91) mengemukakan Sumberdaya tersebut dapat terwujud sumberdaya manusia, yakni kompetensi implementator, dan sumberdaya finansial. Sumberdaya adalah faktor penting untuk implementasi kebijakan agar efektif. Tanpa sumberdaya kebijakan hanya akan menjadi sekedar dokumen. Meskipun isi kebijakan telah dikomunikasikan secara jelas dan konsisten, tetapi apabila implementator kekurangan sumberdaya untuk melaksanakan, implementasi tidak akan berjalan efektif.

Dalam hal ini sumberdaya manusia terkait pelaksanaan adiwiyata di Madrasah Aliyah Negeri 2 Kulon Progo adalah semua warga sekolah terlibat dalam pelaksanaan adiwiyata ini, namun demikian sekolah tetap membentuk tim inti adiwiyata sekolah dan tim adiwiyata siswa. Terkait sumber dana, sekolah mendapatkan dana untuk pelaksanaan adiwiyata ini berasal dari anggaran nasional dan komite sekolah. Selanjutnya untuk alokasi waktu yaitu pelaksanaan adiwiyata ini dilaksanakan setiap hari Jumat pagi sebelum kegiatan belajar mengajar berlangsung.

c. Disposisi

Edward III dalam (Subarsono, 2008: 9192) mengemukakan Disposisi merupakan watak dan karakteristik yang dimiliki oleh implementor, seperti komitmen, kejujuran, sifat demokratis. Apabila implementasor memiliki disposisi yang baik, maka dia akan dapat menjalankan kebijakan dengan baik seperti apa yang diinginkan oleh pembuat kebijakan. Ketika implementor memiliki sikap atau perspektif yang berbeda dengan pembuat kebijakan, maka proses implementasi kebijakan akan menjadi tidak efektif.

Dalam kaitannya dengan pelaksanaan adiwiyata di Madrasah Aliyah Negeri 2 Kulon Progo para implementator kebijakan yang ada di sekolah sudah menunjukan kemampuan yang memadai, selain itu kepala sekolah dan tim adiwiyataa sekolah berkomitmen menjalankan kegiatan adiwiyata secara berkesinambungan.

\section{d. Struktur Birokrasi}

Edward III dalam (Subarsono, 2008: 92) menjelaskan Struktur organisasi yang bertugas mengimplementasikan kebijakan memiliki pengaruh yang signifikan terhadap implementasi kebijakan. Salah satu dari aspek struktur yang penting dari setiap organisasi adalah adanya prosedur operasi yang standar (Standard operating procedures atau SOP), SOP menjadi 
pedoman bagi setiap implementor dalam bertindak. Struktur organisasi yang terlalu panjang akan cenderung melemahkan pengawasan panjang akan cenderung melemahkan pengawasan dan menimbulkan redtape, yakni prosedur birokrasi yang rumit dan kompleks. Hal ini pada gilirannya menyebabkan aktivitas organisasi yang tidak fleksibel.

Dalam hal ini struktur birokrasi yang di buat sekolah adalah dengan membentuk tim adiwiyata sekolah. Tim adiwiyata sekolah disahkan dengan dibuatkan SK Kepala Sekolah. Semua kegiatan adiwiyata akan dievaluasi dan dipertanggungjawabkan kepada kepala sekolah, dalam SK tersebut juga memuat job deskripsi dari struktur organisasi, sehingga memudahkan pelaksana kebijakan dalam melaksanakan tugastugas dan tanggungjawabnya dilapangan.

\section{Program Yang Dilaksanakan Di Madrasah Aliyah Negeri 2 Kulon Progo Dalam Upaya Penanaman Nilai Peduli Lingkungan}

Pengimplementasian adiwiyata tersebut telah disesuaikan berdasarkan empat komponen adiwiyata, kemudian dilaksanakan dalam berbagai kegiatan, antara lain sebagai berikut: Green House, Bank Sampah, Komposter, Keindahan dan Kebersihan Lingkungan, dan Kreasi Sampah.

Program yang pertama adalah Komposter atau pengolahan kompos. Kompos merupakan hasil penguraian parsial/tidak lengkap dari campuran bahan-bahan organik yang dapat di percepat secara artifisial oleh populasi berbagai macam mikroba dalam kondisi lingkungan yang hangat, lembab, dan aerobik atau anaerobik. (J.H. Crawford, 2003). Sedangkan pengomposan adalah proses dimana bahan organik mengalami penguraian secara biologis, khususnya oleh mikroba-mikroba yang memanfaatkan bahan organik sebagai sumber energi. Membuat kompos adalah mengatur dan mengontrol proses alami tersebut agar kompos dapaat terbentuk lebih cepat. Kegiatan yang dilakukan yaitu mengelola kompos padat mandiri pengumpulan daun, Pembuatan, Pengolahan dan pengepakan sampah organik menjadi kompos padat. Pada kegiatan ini terdapat satu penanggung jawab yang membina siswa-siswi yang tergabung dalam kegiatan ini, tujuan dari program ini adalah untuk memanfaatkan sampah organik dari lingkungan sekolah untuk dapat dimanfaatkan sebaik mungkin.

Program kedua yang di selenggarakan oleh sekolah yaitu green house, terdapat dua jenis green house di madrasah ini yang pertama adalah greenhouse tanaman sayur yang terdiri dari beberapa sayuran mulai dari selada, bayam dan sawi. Green house yang kedua yang masih tergolong baru yaitu green house taman anggrek, green haouse taman anggrek ini menyediakan berbagai jenis tanaman anggrek, mulai dari anggrek canttleya sampai anggrek oncidium. Green house ini bertujuan untuk mengenalkan cara merawat dan menyayangi tanaman pada siswa.

Kemudian program ketiga yaitu Bank sampah, kegiatan dari bank sampah ini di mulai dari menyediakan tempat pilah sampah sesuai jenisnya, kemudian memilah sampah sesuai jenisnya yang mana sampah plastik seperti botol air mineral dikumpulkan dalam karung atau keranjang hingga terkumpul cukup banyak kemudian hasil dari pengumpulan selama beberapa waktu tersebut di jual kepada pengepul sampah, sehingga pada program bank sampah ini, selain dapat membiasakan siswa untuk mampu memilah sampah dengan baik juga untuk dapat menghasilkan keuntungan sendiri melalui penjualan sampah-sampah plastik.

Program keempat yakni tentang kebersihan dan keindahan lingkungan sekolah, kegiatan ini dilakukan dengan membersihkan halaman sekolah, mulai dari menyapu, mengepel lantai, menyirami tanaman, mencabuti rumput ilalang dan juga merawat tanaman-tanaman yang ada dilingkungan sekolah agar lingkungan sekolah luar maupun dalam kelas terlihat bersih dan nyaman untuk kegiatan belajar mengajar sehari-hari. Program terakhir yang di selenggarakan yakni kreasi sampah, kreasi sampah sendiri adalah pemanfaatan barangbarang bekas seperti botol plastik, bungkus makanan plastik yang dapat di olah menjadi kerajinan maupun barang yang bernilai guna.

\section{Kendala yang dihadapi dalam} Implementasi Kebijakan Adiwiyata Sebagai Upaya Penanaman Nilai Peduli Lingkungan di Madrasah Aliyah Negeri 2 Kulon Progo

Kendala dalam pelaksanaan kebijakan adiwiyata dalam upaya penanaman nilai peduli lingkungan yang dilaksanakan di Madrasah Aliyah 
Negeri 2 Kulon Progo lebih pada pembiasaan pada siswa yang masih kurang peduli terhadap lingkungan sekolah dan cenderung menyepelekan hal-hal seperti membuang sampah tidak pada tempat pilah sampah. Untuk merubah kebiasaan siswa sangat sulit dan membutuhkan proses yang tidak sebentar.

\section{SIMPULAN DAN}

\section{SARAN Simpulan}

1. Implementasi Kebijakan Adiwiyata Di Madrasah Aliyah Negeri 2 Kulon Progo melalui empat aspek menurut Edward III yang meliputi: Komunikasi, disposisi, sumberdaya dan struktur birokrasi adalah sebagai berikut:

a. Komunikasi

1.) Komunikasi dengan pelaksana kebijakan Komunikasi dalam pelaksanan kebijakan dilakukan dengan cara membangun realasi dengan Dinas Lingkungan Hidup Kabupaten Kulon Progo dan Puskesmas Daerah. Selain itu sekolah juga sering mengundang puskesmas daerah untuk memberikan sosialisasi.

2.) Komunikasi dengan wali siswa dan siswa Komunikasi dengan wali siswa dilakukan sekolah melalui komite, yaitu rapat komite sedangkan dengan siswa sekolah juga membentuk tim adiwiyata siswa. Selain itu sekolah juga memanfaatkan media social seperti melalui Whatsapp.

b. Sumberdaya

1.) Sumberdaya Manusia

Sumberdaya manusia untuk melaksanakan kegiatan atau program adwiyata di Madrasah Aliyah Negeri 2 Kulon Progo adaalh Tim Adwiyata sekolah, Tim Adiwiyata siswa dan semua warga sekolah ikut terlibat dalam setiap kegiatan Adiwiyata yang dilaksanakan.

\section{2.) Sumberdana}

Sumberdana yang digunakan dalan setiap kegiatan adiwiyata ini berasal dari anggaran adiwiyata nasional dan komite.

3.) Alokasi Waktu

Alokasi waktu yang digunakan pada setiap kegiatan adiwiyata yaitu setiap hari jumat sebelum kegiatan belajar mengajar berlangsung.

\section{c. Disposisi}

Pelaksana kebijakan adiwiyata di Madrasah Aliyah Negeri 2 Kulon Progo sangat berkomitmen, hal ini dibuktikan dengan perencanaan dan pelaksanaan program adiwiyata secara berkesinambungan.

d. Struktur Birokrasi

Struktur birokrasi dituangkan ke dalam bentuk pembuatan Surat Keputusan Kepala Sekolah Tentang Pembentukan Tim Adiwiyata Di Madrasah Aliyah Negeri 2 Kulon Progo, dimana kepala sekolah sebagai penanggung jawab program adiwiyata dan dibantu oleh ketua tim, guru, dan karyawan yang tergabung dalam tim adiwiyata sekolah sebagai pelaksanan inti. Dalam Surat Keputusan yang dibuat oleh kepala sekolah tersebut sudah memuat deskripsi tugas yang memudahkan pelaksana kebijakan dalam melakukan tugasnya.

2. Program yang dilakukan Madrasah Aliyah Negeri 2 Kulon Progo dalam upaya penanaman nilai peduli lingkungan meliputi beberapa program sebagai berikut:

a. Program yang dilaksanakan, terdapat beberapa program yang dilaksanakan di Madrasah Aliyah Negeri 2 Kulon Progo, yaitu meliputi:

1.) Green House terdiri dari Green House tanaman sayuran dan Green House tanaman Anggrek.

2.) Bank Sampah, yaitu pengumpulan sampah-sampah yang bernilai guna dan bernilai jual.

3.) Komposter, yaitu pembuatan kompos melalui sampah-sampah organik.

4.) Kebersihan dan Keindahan Lingkungan, yaitu merawat, menyayangi dan menyirami tanaman di lingkungan sekolah.

5.) Kreasi Sampah, yaitu membuat kreasi atau kerajinan tangan melalui sampah plastik.

3. Kendala yang dihadapi sekolah dalam Implementasi Kebijakan Adiwiyata Sebagai Upaya Penanaman Nilai Peduli Lingkungan Di Madrasah Aliyan Negeri 2 Kulon Progo sebagai Berikut:

Kendala yang dihadapi sekolah adalah masih sulit membiasakan siswa untuk tertib mentaati 
aturan seperti halnya membuang sampah pada tempat pilah sampah

\section{Saran}

Setelah melakukan penelitian mengenai Implementasi Kebijakan Adiwiyata Sebagai Upaya Penanaman Nilai Peduli Lingkungan di Madrasah Aliyah Negeri 2 Kulon Progo, peneliti memberi saran sebagai berikut:

1. Perlunya sekolah menambah relasi dengan lembaga-lembaga terkait, dan mengadakan sosialisasi mengenai peduli lingkungan.

2. Perlunya penambahan fasilitas pada setiap program yang dilaksanakan agar pelaksanaan program berjalan dengan baik.

3. Perlunya mengatur alokasi waktu untuk kegiatan adiwiyata agar semua program dapat terlaksana secara baik.

\section{DAFTAR PUSTAKA}

Emzir. (2012). Metodologi Penelitian Kualitatif Analisis Data. Jakarta: PT Raja Grafindo Persada.

Herdiansyah Haris. (2013). Wawancara, Observasi, Focus Group. Jakarta: Rajawali Pers.

Kementerian Lingkungan Hidup dan Kementerian Pendidikan dan Kebudayaan. (2013). "Panduan

Adiwiyata: Sekolah Peduli danBerbudaya Lingkungan". Jawa Tengah: Badan Lingkungan Hidup.

Kurniasih, I. (2007) Pendidikan Karakter Internalisasi dan Metode Pembelajaran di Sekolah. Kata Pena.

Fajarisma, Adam Budi. (2014). "Analisis Implementasi Kebijakan Kurikulum Berbasis Lingkungan Hidup Pada Program Adiwiyata Mandiri di SDN Dinoyo Malang”. Jurnal Kebijakan dan Pengembangan Pendidikan (Volume 2, Nomor 2, Juli 2014) Hlm. 166-173

Hasbullah. (2016). Kebijakan Pendidikan: Dalam Perspektif Teori, Aplikasi, dan Kondisi Objektif Pendidikan di Indonesia. Jakarta: Rajawali Press.

Najib M, dkk (2016). Manajemen Strategik Pendidikan Karakter Bagi Anak Usia Dini. Yogyakarta. Gava Media
Nurul Zuriah.(2006).Metodologi Penelitian Sosial dan Pendidikan: Teori Aplikasi. Jakarta: PT Bumi Aksara.

Peraturan Menteri Negara Lingkungan Hidup No 02 Tahun 2009 Pasal 1 ayat 2 tentang Pedoman Pelaksanaan Program Adiwiyata. 